\title{
On the issue of the legal status of persons exercising control of a maritime autonomous surface vessel
}

\author{
Anastasiya Golovina* \\ Admiral Ushakov Maritime State University, 93, Lenin`s avenue, Novorossisk, 353918, Russia
}

\begin{abstract}
The article is devoted to the study of some problematic aspects of the legislative consolidation of the legal status of a person exercising control of a maritime autonomous surface vessel. The author considers the issues of the need to determine the scope of the functions performed by a given person at the legislative level and his responsibility, a set of rights and obligations, features of vocational training, retraining and certification, requirements for competencies, peculiarities of the work duties implementation, as well as the necessary nomenclative apparatus in the legislation of the Russian Federation. The article reveals main brief conclusions of the analysis of basic implemented measures, providing for amendments to the current legislation in the field of public relations regulation arising in the sphere of operation of autonomous maritime surface vessels and, in particular, in the sphere of the legal status of persons managing the given technical unities. Based on the current legislation analysis in the area under consideration, the author offers some recommendations for its further development, and also highlights the main areas to be regulated, considering the need for research in order to create the required rules and regulations that ensure the navigation safety in the framework of the operation of maritime autonomous surface vessels.
\end{abstract}

\section{Introduction}

Marine transport plays a strategically significant role for Russia, as a factor of internal socio-economic development, and its integration with the world economy [1]. Currently, one of the most promising areas for the transport complex development is autonomous (unmanned) navigation. It seems, for example, that the use of technical unities of the given type will reduce the accident rate which is often associated with a human factor, and will reduce the downtime of ships in the raids, the implementation of high-precision sea and cargo operations, and etc.

Researchers also note the interest of commercial structures in introducing the practice of unmanned navigation within the framework of marine transport in order to reduce operating costs, which include a significant part of the salaries of ship crews [2], and the expenditures of repatriating crew members.

However, at present, the processes of design, creation and operation of such technical unities (including the experiment stage) raise numerous issues from the standpoint of the legal regulation of the given areas of activity and the determination of the possibility of applying the rules and regulations governing similar relations within the framework of "classical" navigation. The issues of designating the legal status of persons directly managing autonomous vessels are essential in this area.
Despite the fact that the human factor is the main cause of accidents in marine transport, according to researchers [3], it is impossible to assert that the absence of a person on the vessel board excludes the occurrence of various risks to the cargo, the vessel, the environment which indicates the need to resolve issues related to the control of unmanned vessels.

Owing to the fact that existing rules and regulations are one of the tools to ensure the navigation safety, consideration of their applicability to relations arising in the framework of autonomous navigation, as well as the development of appropriate additions to the current regulatory system are essential steps in the extension of the entire industry.

\section{Problem statement}

The issues of legal regulation of relations arising in the framework of the creation and operation of vessels with a high level of autonomy (including unmanned marine vessels) are of interest both at the international level and at the level of individual states. The International Maritime Organization (hereinafter - IMO) plays a special role in the development of rules for the safe operation of the considered technical unities.

The four levels of maritime autonomous surface vessels (hereinafter - MASC), presented in Table 1, were allocated for the purposes of autonomous navigation in the framework of the $99^{\text {th }}$ session of IMO in 2018 to

\footnotetext{
Corresponding author: a.a.golovina@mail.ru
} 
facilitate the work on both the determination and the applicability of existing legal instruments of IMO.

Table 1. Levels of surface vessels autonomy

\begin{tabular}{|c|c|}
\hline No & Feature \\
\hline 1 & Vessel with automated processes and decision support \\
\hline 2 & $\begin{array}{c}\text { Remote control vessel } \\
\text { (sailors on board) }\end{array}$ \\
\hline 3 & $\begin{array}{c}\text { Remote control vessel } \\
\text { (no sailors on board) }\end{array}$ \\
\hline 4 & Completely autonomous vessel \\
\hline
\end{tabular}

Analyzing the proposed classification, it can be concluded that at present there is no need to determine the legal status of specialists involved in managing vessels of the first among the above levels, since such vessels actually include those that are successfully operated at the present time. Thus, the existing legal regulation in this part can be considered sufficient and meeting current needs to the required extent. The fourth level, taking into account its characteristics, currently does not arouse interest in the field under consideration.

Moreover, the definition is necessary for the legal status of persons who control vessels of the second and third levels of autonomy from the above classification considering the expected scope of functions that they should be endowed with, as well as the actual absence of the given persons on the vessel board.

It should be noted that nowadays legally enshrined terms being necessary to determine the subject of legal regulation of the relevant relations are absent [4].

The existing Russian legislation (Article 61 of the Merchant Shipping Code of the Russian Federation hereinafter RF MSC) contains a provision according to which vessel control, including navigation, taking measures to ensure the safe navigation of the vessel, protect the marine environment, maintain order on the vessel, prevent harm to the vessel, people and cargo on board, is assigned to the captain of the vessel. It appears that, in its most general form, the person controlling MASC remotely carries out a similar range of responsibilities with exemptions related to the essence of the autonomous navigation concept. Besides, it does not seem correct to identify the concepts of "captain of a vessel" with a concept that in the future will denote a person who controls an autonomous vessel remotely, as well as the identification of their duties related to the vessel control, and the scope of responsibility.

It can be possible to find various terms used by researchers to designate a person who controls an autonomous vessel remotely (for example, "operator", "external captain" [5], and etc.) due to the lack of a unified terminological apparatus in this area when studying scientific literature. There is no doubt that the use of the term "sailor" does not seem correct to refer to the given specialists, since an analysis of the current provisions of international and Russian law shows that they may include persons carrying out their professional activities directly on the vessel board, and it contradicts the MASC operating concept. This, in turn, confirms the need, firstly, to consolidate the appropriate terminological apparatus, and, secondly, to specifically define the peculiarities of the legal status of specialists who control autonomous vessels remotely, as well as a detailed study of the applicability of the rules governing the peculiarities of the sailors' legal status in this area.

It is essential to reach an understanding in the essence of MASC, considering the classification of these technical means by the autonomy level given in Table 1, which is a prerequisite for revising the legal status of sailors, if they are still on the vessel board (assumed by the $1^{\text {st }}$ and $2^{\text {nd }}$ levels of autonomy in the above classification). As mentioned above, the legal status of sailors carrying out their professional activities on a vessel with automated processes and decision-making support is actually enshrined in the current norms of Russian, foreign and international law, while the legal status of a sailor working on a vessel with remote control (with an application of such a model in the future) raises some issues.

\section{Materials and methods}

Attempts to implement such developments are carried out at the level of domestic legislation. It should be noted that the relevant measures were to be implemented in accordance with the Order of the Government of the Russian Federation of March 29, 2018 N 534-r "On the arrangement plan ("road map") to improve legislation and eliminate administrative barriers in order to ensure the implementation of the National Technology Initiative on "Marinet" direction." For instance, "the development of the conceptual apparatus, including the terms of "unmanned vessel", "external captain", was enclosed in the Plan.

However, on January 21, 2020, this document became invalid due to the release of the Government Order dated January 21, 2020 with the same appellation. The given document established a plan to implement similar activities until September 2020. However, some of the wordings of the part of interest have been changed in a new plan. For example, the task of developing the concept of "autonomous vessel" was stated instead of developing the concept of "unmanned vessel." The term "external captain" was not included in the plan. Subsequently, this order was subjected to changes that did not affect the field under consideration.

The indicated measures were implemented within the framework of the preparation of the Federal Law Draft by the Ministry of Industry and Trade of Russia "On Amendments to the Merchant Shipping Code of the Russian Federation and certain legislative acts of the Russian Federation in terms of legal relations arising from the use of autonomous vessels" (hereinafter - the Draft).

The Draft provided for the addition of the current RF MSC with a provision fixing the concept of an autonomous vessel, which meant "a self-propelled vessel, the control processes of which are partially or completely carried out in automatic mode without the participation of the vessel crew." The Draft envisaged 2 
types of such vessels depending on the automation degree:

- Semi-autonomous vessel (the degree of automation does not carry out constant control over the vessel's machinery, mechanisms and devices (keep a navigational watch), and also does not constantly control the vessel movement by the crew forces which conducts general supervision of the vessel and, if necessary, controls the vessel, its machines and mechanisms, or not to control the vessel movement by the crew forces which conducts general supervision of the vessel and, if necessary, takes measures to restore normal operation of the vessel's machinery, mechanisms, and devices).

- Completely autonomous vessel (the vessel automation degree allows it to sail without a crew on board while monitoring the vessel and controlling its movement by specialists in autonomous vessel control outside the vessel, or without constant supervision and control of the vessel by specialists in autonomous vessel control outside the vessel).

It is significant to note that this approach differs from the one proposed by IMO in 2018 but excludes the issues of the need to determine the specifics of the legal status of sailors working on a vessel with remote control (par. 3 , Table 1), suggesting the development of appropriate provisions in relation to the person carrying out MASC control remotely.

The Draft also provided for the addition of RF MSC with chapter VI.1 "Features of the autonomous vessel operation." This chapter was supposed to include Art. 106.5, establishing the provision according to which "a specialist controlling autonomous vessels with experience in the position of captain or chief mate of a maritime vessel with a tonnage of at least 3,000 and completed training in the advanced training program in the field of controlling autonomous vessels, or a specialist with a higher technical education and completed a professional retraining program in the field of controlling autonomous vessels should control an autonomous vessel remotely or assist the crew of an autonomous vessel in operating an autonomous vessel."

Besides, the Draft envisaged the addition of RF MSC with provisions establishing requirements for the person operating an autonomous vessel.

\section{Results and Discussion}

The above approach, and some other provisions of the Draft, is contradictory. For instance, we can assume some potential difficulties in the practice of applying the proposed rules related to the following factors:

- A number of the proposed provisions, which are of fundamental importance in the framework of the legal regulation of relations arising in the field of autonomous navigation, have excessively narrow wordings, or are not specified to the required degree.

- Incomplete conformity of the Draft provisions with some norms of domestic legislation and the provisions of international treaties of the Russian Federation.
- Differences in the approaches proposed by the Draft and IMO (for example, in terms of the classification of MASC autonomy levels).

The conclusion is that the changes proposed by the Draft are not able to completely ensure the navigation safety in the framework of the MASC operation. The given shortcomings were reflected in the Expert opinion on Draft N 204-7/2020, adopted on December 17, 2020 at a meeting of the Council under the President of the Russian Federation for the codification and improvement of civil legislation, with the conclusion about an inability to maintain the Draft.

Thus, the problem of the lack of the concept legislative consolidation, signs and classification of autonomous vessels, as well as the peculiarities of the legal status of persons controlling such technical unities at the level of the national legislation of the Russian Federation has not been resolved yet.

Considering the prospects for the active development of the unmanned navigation industry, work performance is required not only in terms of developing new norms, but also analyzing the current regulatory legal acts governing the legal status of persons who control "classic" vessels in terms of their applicability to persons controlling MASC. The provisions of the given regulatory legal acts within the framework of such work must be divided into 3 groups, taking into account the above subject:

- norms that are not applicable in the MASC control environment;

- norms that are applied in the MASC control conditions requiring adjustment;

- norms that are applied in the MASC control conditions without adjustment.

Carrying out such analytical work with considering the peculiarities of the autonomous vessel operation is a substantial condition for effective legal regulation of the legal status of persons controlling MASC, and will minimize feasible gaps and conflicts.

It is important to note that the current Russian legislation in RF MSC contains the term of "captain of a towing vessel" who carries out sea towing, speaking of the prospect of using unmanned tows as one of the possible types of MASC. The norms of domestic maritime law fix the peculiarities of the legal status of such a person, his duties, rights, responsibilities, and etc.

The MASC concept does not theoretically provide for the presence of the towing vessel captain (in the classical sense) on board, since such a technical unit will be controlled by a specialist remotely, or through the use of artificial intelligence technologies.

The given provision raises a number of issues. Firstly, the application of existing norms of the current legislation in the field of distribution of rights and obligations between the parties to the towing relationship in the operating conditions of an unmanned tow is not correct due to the lack of features characteristic of autonomous navigation. As noted above, the prospect of equating the "captain of the vessel" with the "person controlling an autonomous vessel" cannot be considered 
correct considering the functional uncertainty of the latter [6].

Moreover, the prospects for the application of the current norms on civil, administrative, criminal liability for harm caused by the MASC operation are to be studied. It is obvious that, for example, Art. 270 of the Criminal Code of the Russian Federation which provides for the offensive of criminal liability for the assistance failure by the vessel captain to those in distress at sea, is not applied in the operating conditions of an autonomous vessel controlled remotely. The given duty in its classical sense cannot be assigned to the person who controls MASC remotely. Human life is the most important value, and the introduction of the autonomous navigation practice does not exclude the human presence at sea. Therefore, it is necessary to consider the possibility of imposing an appropriate responsibility on the specified specialist in the future (for example, to inform the authorized services about the identified threat to human life at sea as part of actions for the remote control of an autonomous vessel in the event that the identification of such a threat will be technologically feasible).

According to the fair statement of researchers, environmental safety is the most essential after the safety of life and the vessel, which enjoys the highest priority [7]. The liability issue for causing damage to this interest in the conditions of MASC operation is subject to the detailed analysis. If, for instance, the vessel owner bears civil liability in the event of oil pollution of the sea (which is applicable in the concept of autonomous navigation), then the person obliged to comply with the requirements for protecting the marine environment from harmful influences is subject to liability in case the emergence of signs envisaged by Art. 252 of the Criminal Code of the Russian Federation ("Water Pollution"). Compliance with these rules should be included in the list of responsibilities of the person who operates MASC remotely.

Thus, it is necessary to legislate the scope and content of the functions performed by the person being in charge of controlling the autonomous tow to ensure the navigation safety in the MASC operating conditions. The rights and obligations of such a person should be described in as much detail as possible [8].

\section{Conclusion}

The lack of a unified approach to the definition of the term "autonomous vessel" and the lack of signs of such a vessel, enshrined in the rules of law, as well as signs and a single name for the person in charge of the vessel, complicates the subsequent work to determine its legal status. The absence of a uniform comprehension of the entire scope of technical features of the vehicles under consideration, which are significant in determining the functions of the persons driving them, complicates the work on legislative consolidation of the relevant rules and procedures. At the same time, the extension of the norms on the legal status of vessel captains or other crew members to such specialists does not seem correct.
The development and subsequent legislative consolidation of the provisions governing relations in the basic areas are substantial considering the tasks of the MASC control specialist within the framework of the definition and subsequent legislative consolidation of his legal status:

- The scope and content of the performed functions in controlling an autonomous vessel (the rights and obligations of a person related to the implementation of the functions assigned to him should be described as detailed and accurately as possible to avoid difficulties in the framework of law enforcement practice).

- Education (including supplementary education and (or) professional retraining) with the obligatory determination of the amount of knowledge, skills and abilities that such a person must possess, as well as methods for assessing the quality level of specialists' activities [9]. The training program of disciplines and practical parts aimed at developing knowledge, skills and abilities to control the vessel using remote control technologies is significant. Besides, it is necessary to consolidate the assessment criteria for the development of relevant competencies within the framework of the intermediate and final certification of the student, and the form of certification [10]. The issues of differentiating the requirements for the content of educational programs for specialists controlling various types of the given technical unities are subject to research, taking into account the potential classification of MASC.

- Work experience. It is indispensable to include the requirements for the availability of work experience on a non-autonomous vessel for a specialist operating a marine autonomous vessel (the requirement proposed by the Project in this part can be noted considering the need to fix a specific period of work on a vessel, and not only the fact of work experience).

- Issues of liability for damage caused by an autonomous vessel through the fault of such a person (including the distribution of liability between a person and the vessel owner).

- Features of labor activity. For example, the determination of the probable characteristics of the time of work and rest is required for the specialists controlling MASC with consideration to the constant control of the vessels being operated, as well as the applied technologies.

The definition of the indicated provisions will make it possible to carry out work on the study of the applicability of existing norms in this area used in similar social relations arising in the framework of "classical" (non-autonomous) navigation. It is mandatory to develop an appropriate term and consolidate its definition, both at the level of international norms and national legislation of individual states for the uniform application of the training rules and certification of such persons, determining the level of their responsibility and the scope of performed functions.

It should be noted that the development and subsequent legislative consolidation of norms aimed at regulating the legal status of persons controlling MASC 
is complicated by the fact that autonomous navigation, as a separate industry, is at the initial stage of its progress, that is, the issues described above are inherent. The noted direction is promising and will actively develop in the near future, which in turn will contribute to the emergence of new social relations and, as a consequence, the growing need for their regulation.

The development of provisions on the legal status of a person who controls an autonomous vessel can be efficiently implemented only after the relevant work in terms of defining the operation features of an autonomous vessel. It is significant to achieve a uniform comprehension of the main number of issues in the area under consideration at the international level before carrying out the corresponding work by individual states in order to exclude feasible conflicts that could complicate the law enforcement process.

\section{References}

1. O.N. Baburina, M.V. Botnaruyk, S.I. Kondratiev, Marine intellectual technologies, 3(41), 1, 190-198 (2018).
2. A.G. Zelenkov, V.V. Ustinov, M.S. Lopatin, Marine intellectual technologies, 4(3), 111-119 (2019).

3. A.I. Epikhin, E.V. Hekert, M.A. Modina, Marine intellectual technologies, 2(52), 2, 38-46 (2021).

4. V.V. Zaslonov, A.A. Golovina, A.N. Popov, Lecture Notes in Networks and Systems, 1(115), 468-474 (2020).

5. S.N. Zaikova, A.V. Titov, Transport of Russian Federation, 5(78), 50-53 (2018).

6. V.V. Zaslonov, A.A. Golovina, Marine intellectual technologies, 2(52), 2, 132-139 (2021).

7. V.A. Turkin, D.A. Davydov, A.A. Styazhkin, Marine intellectual technologies, 2(52), 2, 58-66 (2021).

8. S.K. Abrahamyan, K.V. Golubkina, Marine intellectual technologies, 1(43), 2, 82-85 (2019).

9. A.N. Pechnikov, E.V. Khekert, Marine intellectual technologies, 4(3), 101-110 (2019).

10. A.L. Boran-Keshishyan, S.I. Kondratiev, A.N. Tomilin, Marine intellectual technologies, 1(43), 2, 149-156 (2019). 